\title{
INSTITUCIONES SOCIORRELIGIOSAS JUDÍAS DE ZARAGOZA (SIGLOS XIV-XV) SINAGOGAS, COFRADÍAS, HOSPITALES *
}

ASUNCIÓN BLASCO MARTÍNEZ

Universidad de Zaragoza

\section{CONCLUSIONES}

Después de realizar este minucioso estudio sobre las instituciones benéficas y asistenciales de los judíos zaragozanos en los siglos XIV y $\mathrm{XV}$, se puede concluir que:

- Las cofradías eran, simultáneamente, asociaciones de ayuda mutua y de beneficiencia.

- Dichas hermandades, cuando no tenían oratorio propio, solían estar adscritas a una sinagoga.

- Para constituir cofradía era imprescindible contar con la licencia del rey.

- Toda cofradía se regía por unos estatutos refrendados por el monarca.

- Cada cofradía tenía sus propios adelantados o mayordomos que la regían y administraban.

- El capital de las cofradías estaba constituido por las cuotas de los asociados y donaciones.

- En Zaragoza coexistía un organismo oficial de beneficiencia (la "Almosna de la aljama») junto con diversas entidades privadas.

- En el siglo XIV se hallaban plenamente afianzadas en dicha ciudad las cofradías de "Hozé-Hezt», «Rotfecédech», "Cefarim» o Atoras, "Talmut Torá,, "Bicorolim», "Cabarim» y de los "Hasquafim». Y en los últimos años de dicha centuria se institu-

* Continuación de SEF XLIX (1989) págs. 227-236 y L (1990) págs. 3-46. 
yeron las de «Lelezmuroz», de "Sombreholim», de «Nozé amitá» y de los Baldreseros.

- En 1378 existía en Zaragoza la cofradía de «Lelezmuroz» o "de Maytinal», prácticamente desconocida en España hasta entonces.

- Se dan a conocer denominaciones nuevas de sociedades conocidas desde antiguo: así, la de "yentes et vinientes", "de maytinal», "del studio», etc.

- Los baldreseros judíos de Zaragoza tenían una asociación que en 1397 contaba con sinagoga propia, como al menos desde 1382 la tenía la cofradía de «Bicorolim».

- En 1485 funcionaba en Zaragoza la cofradía de pellejeros judíos.

- También existían allí diversos hospitales públicos y privados de los que apenas se sabía nada.

- La proliferación de entidades benéfico-asistenciales registradas en Zaragoza durante el último cuarto del siglo XIV pudo ser consecuencia del movimiento populista existente en Aragón por esos años.

- Es posible, pero no segura, la existencia de cofradía de torneros y de plateros judíos.

- Hasta la fecha - mientras no se demuestre lo contrario- la aljama de Zaragoza, con sus numerosas cofradías y hospitales, constituye uno de los mejores exponentes del espíritu filantrópico que animaba a los judíos españoles durante la Baja Edad Media. Quizás por eso, ya en 1415, los conversos de esa ciudad habían conseguido la licencia oportuna para tener su propia almosna ${ }^{355}$.

\footnotetext{
355 1425. II. 6.- «Ramón de Latorre, ciudadano de Caragoça, reptor de la almosna assignada a los conversos por los hondrados los jurados de Çaragoça", recibe de los encargados «de plegar la dita almosna de la parroquia de Sant Pavlo de la dita ciudat” 140 sueldos jaqueses. AHPZ, Pedro Serrano, 1415, fol. 20.
} 


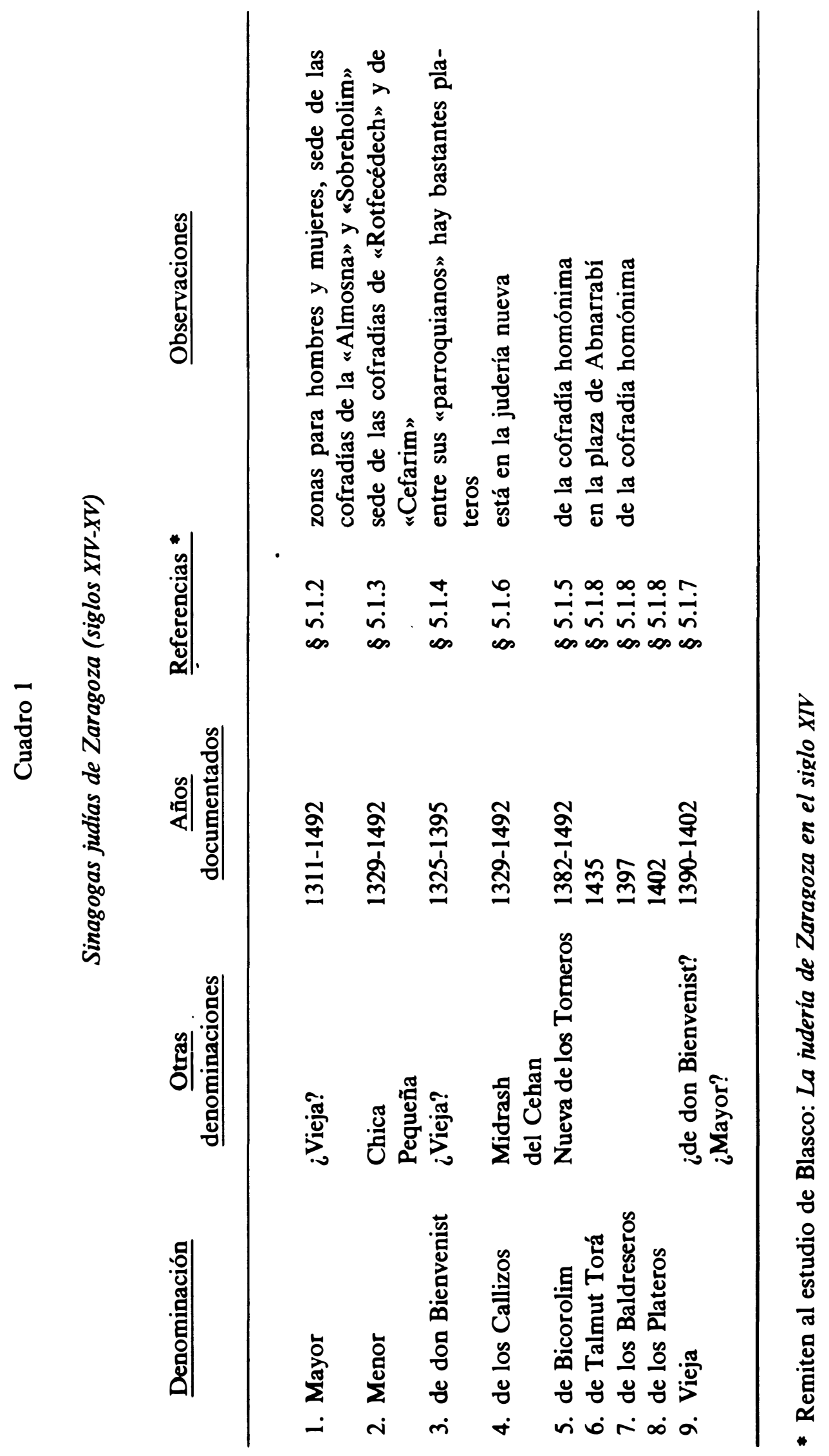




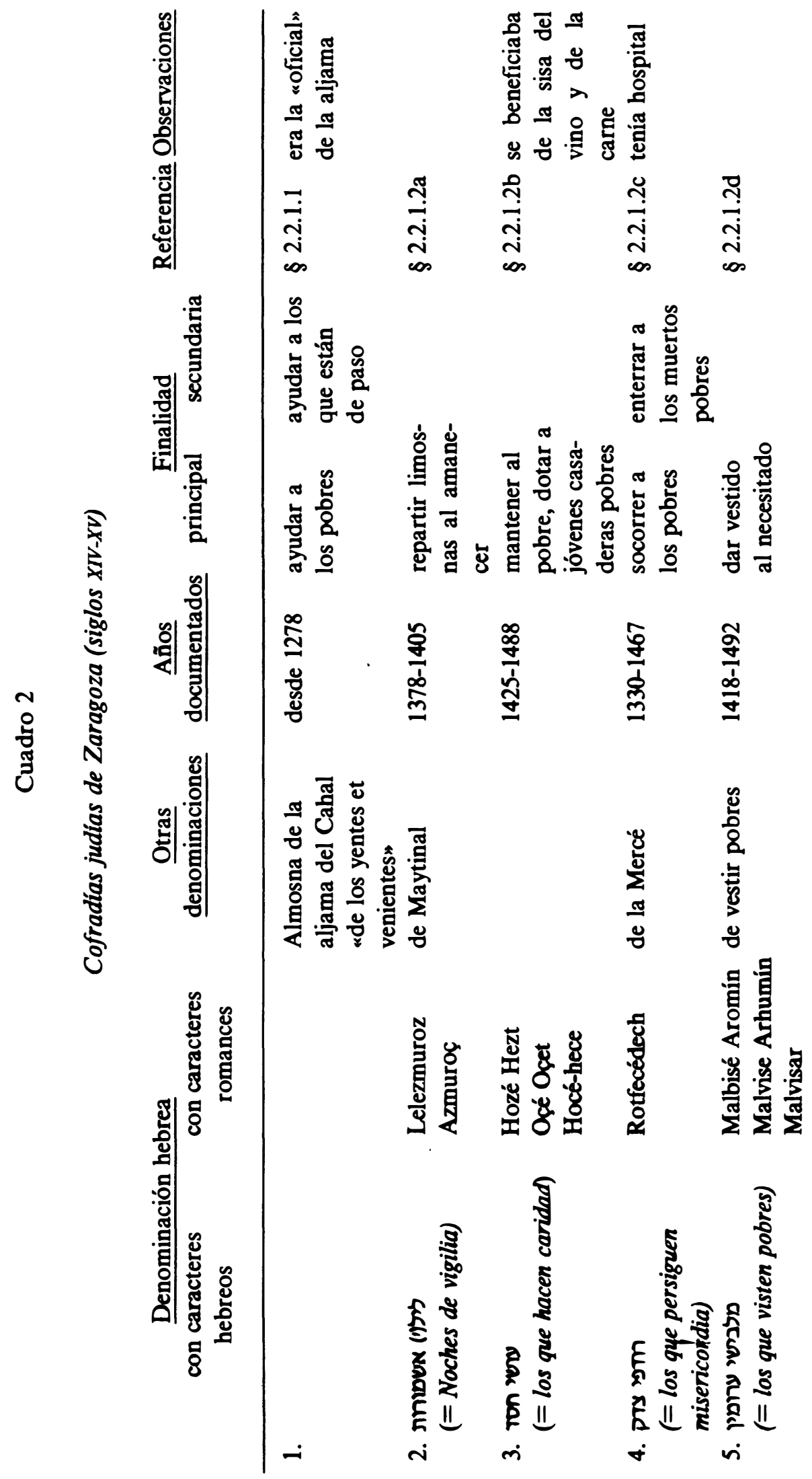



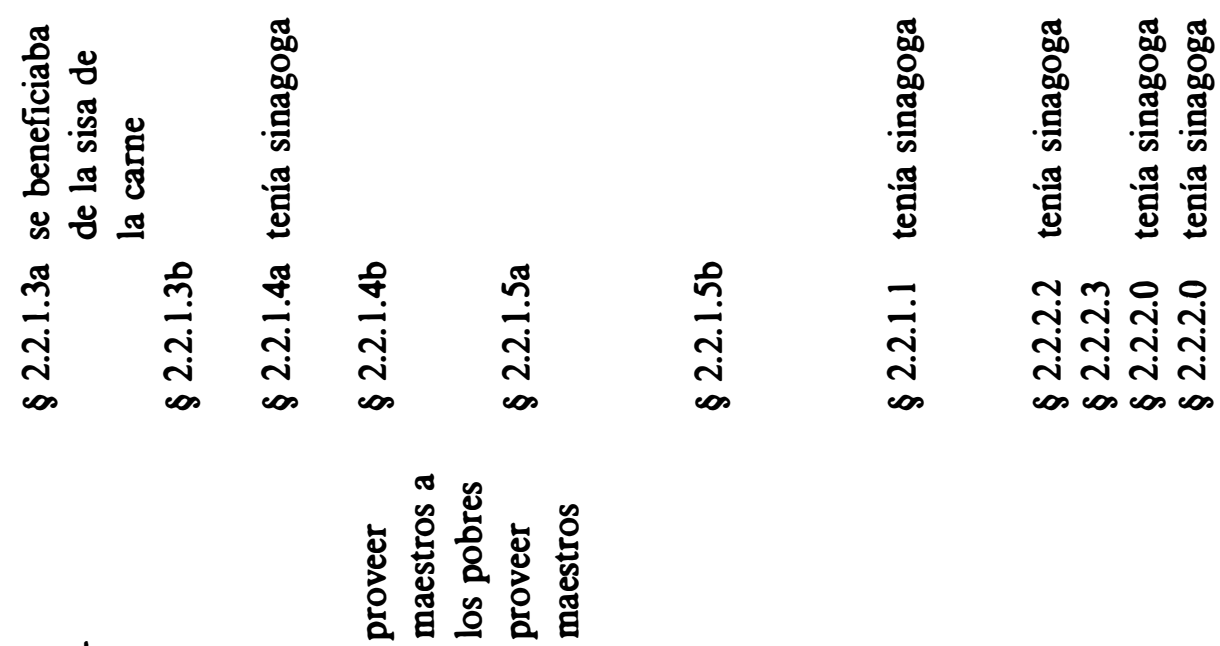

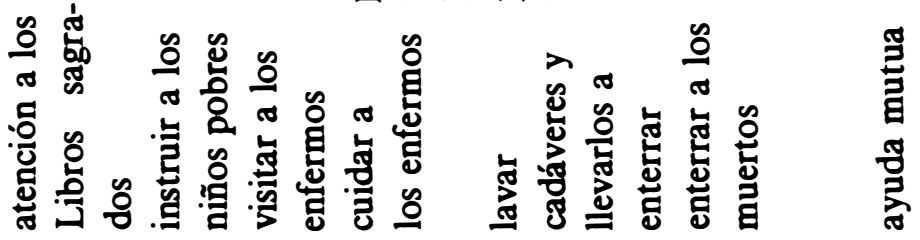

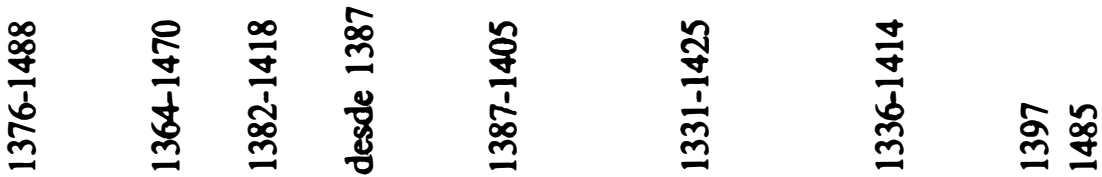

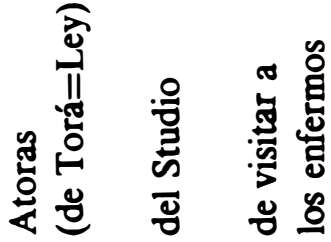

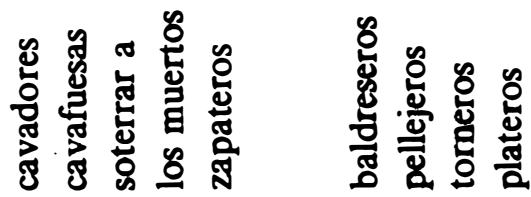

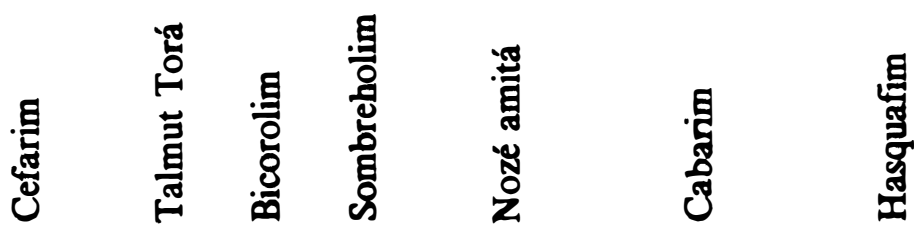

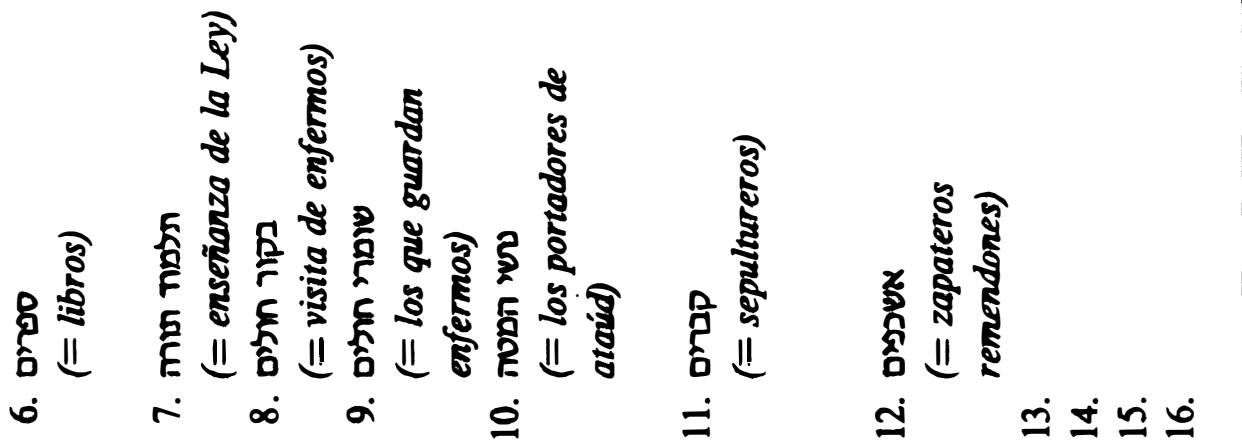




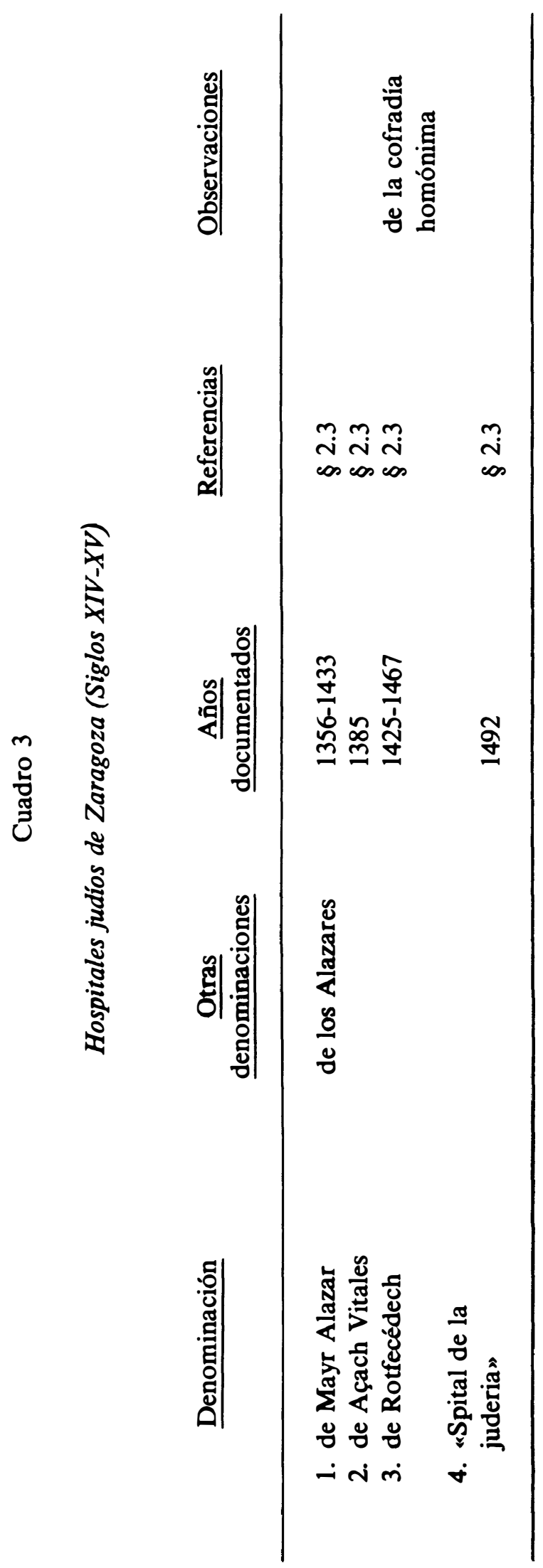


APÉNDICE DOCUMENTAL 356

1330, mayo 3 (Zaragoza).

Los cofrades de la cofradía de enterradores de la Mercé de la aljama de judíos de Zaragoza comisionan a algunos de sus miembros para que negocien con las autoridades cristianas, a fin de resolver las cuestiones suscitadas entre unos cuantos judios de la aljama y un clérigo durante el entierro de un judio indigente.

AHPZ, notario Montaner de Sipán, 1330, fols. 63-64 v.

Conpannya de los enterradores.

Que nos, don Juce Avenrabeç, don Azarias Abnarabi, don Azarias Avendino, do [sic] Abrayn Falleva el mayor, don Cecri Alitienç, don Bonastruç Fedanc, don Achac Afia, don Juce Falleva, Emanu Gallipapa,

${ }^{356}$ La transcripción de los documentos se ha realizado de acuerdo con las directrices generales dictadas en 1944 (véanse las Normas de transcripción y edición de textos y documentos, Madrid, CSIC, 1946) actualizadas en 1983 por la Comisión Internacional de Diplomática reunida en Zaragoza (véanse las Normes Internationales pour l'édition des documents médievaux, en "Travaux préliminaires de la Commission Internationale de Diplomatique et de la Commission Internationale de Sigillographie», Institución Fernando el Católico, Zaragoza 1984, "Folia Caesaraugustana» 1, págs. 15-64).

En este sentido deseo hacer las siguientes puntualizaciones:

1) Se han respetado, en líneas generales, las grafias del original e incluso sus errores ortográficos: cuando se trata de un error patente se ha hecho notar mediante el uso de [sic!].

2) Las palabras y letras suplidas se han incluido entre corchetes.

3) Las lecturas dudosas se han indicado así: (?).

4) Se han separado las palabras de acuerdo con el uso correcto actual, aunque se han respetado algunas contracciones. En caso de contracción en nombres propios, éstos se han separado de la partícula con un apóstrofo.

5) Las palabras compuestas por adverbios o preposiciones se han mantenido unidas, al igual que las expresiones constituidas por una palabra indeclinable y un participio pasado u otro verbo (antedito, sobredito, etc.).

6) Se ha seguido el empleo de mayúsculas aceptado por la ortografia moderna.

7) Se han introducido signos de puntuación actuales, aunque con parquedad.

8) Las abreviaturas, numerosísimas, han sido desarrolladas.

9) Ante el uso indiscriminado de un mismo escribano respecto del empleo de ç, se ha optado por poner cedilla en aquella palabras que generalmente la llevan.

10) El signo tironiano de la conjunción et/e se ha transcrito como et/e de acuerdo con la forma desarrollada que ofrece el documento.

11) Se ha transcrito por $v$ la $u$ con valor de consonante.

12) Se ha respetado la distinción entre $i / j$. 
don Juce Repollat, don Aharon Çaruc, don Abrayn Chiniello, don Jutçe Avenbitas, don Simuel Fichel, don Abrayn Albala fillyo de don Salamon Albala, don Acahc [sic] Onay, don Achac Alitienç, Juhuda Fara, don Achaç Aybari, don Çulema Algazer, don Jesuas Avenamor, judios, parroquianos de la conpannya de los enterradores, de los de la Merce, cridada et plegada la dita conpannya en la sinoga Menor, do otras vegadas yes costunada de plegar, reconoxientes que la dita conpanya yes deputada por merce a cobrir muertos et pobres vergonyants et enterrar, porque muytos de la aljama ante pudirian por las carreras de vergonya ante que non serian enterrados por pobreza; et por esto, en servicio de la dita conpannya, algunos judios flacos, sigyendo $\mathrm{e}[\mathrm{t}]$ levando a enterrar un defunto forano esdevino algun accident entre los judios con un clerigo, los quales fueron acusados criminalment ante el senyor infant don Pedro, primogenito del muyt excellent senyor rey don Alfonso; et porque yes cierto a nos sobreditos que los ditos judios acusados yeran personas pobras et no podian conplir a las mesiones, et sis deviniese alguna cosa seria escarnimiento et avria a cessar la dita merce, ent por esto concordaron los sobreditos, en nopne de la dita conpanya, fecer conposicion con el dito senyor et aver remision del; et por esto nos, sobreditos, en nopne de la dita conpanya queremos et atorgamos et damos pleno poder a don Juce Azageç et don Acahac Jaba, agora ministradores de la dita almosna, et don Juce Avenmori et don Simuel Golluf, fillyo de do [sic] Acahac Golluf, don Mosse Ahuellami et don Bitas Haleva, fillyo [de] don Simuel Halleva, a conponer et conprometer, enpenyar et vender et obligar et firmar sobre los bienes de la dita almosna qualquiere o qualesquiere quantidat o quantidades que sobre la dita razon a ellos bien visto sera o qualquiere otra ordinacion que a ellos bien vista sera, aconsellyo de XXX judios de la dita conpanya. Et encara, fiziemos nos, los sobreditos, todas et cada unas cosas de suso ditas a consellyo et de voluntat de los adelantados de la aliama, yes a saber, don Juhuda Golluf et don Salamon Avenlupiel et don Jento Avenjuda. Et encara, staublimos los especiales et generales procuradores nuestros et de la dita conpaynnya en todos et cada unos pleytos movidos o por mover que nos, enopne [sic] de la dita almosna et conpanya emos o esperamos daver con qualesquiere persona o personas etc. ante el senyor Infant o ante qualquiere juge conpetent eglesiastico et seglar, dants etc., et sustituyr ditos si otro etc., pro me dicientes aver firme etc. feyto, procurado, firmado, vendido sera asi como si de nos et de la dita conpanya fuese feyto, todos obligados dius obligamento de los bienes de la dita almosna. Et obligamos nos pagar todas cosas etc.

Feyto III dias.

Testes: Juhan Porta, portero del sobredito senyor infant don Pedro, et Salamon Paraper, judio de la dita ciudat. 
El rey Pedro el Ceremonioso aprueba el reglamento de la cofradía de los judios zapateros de Zaragoza.

ACA, Reg. 858, fol. $109 \mathrm{v}$.

Documento publicado por BofARULl y DE SARTORIO, Manuel: Colección de Documentos Inéditos del Archivo General de la Corona de Aragón, tomo XL (Barcelona 1876), págs. 131-133.

Noverint universi quod nobis Petro, Dei gratia regi Aragonum, Valentie, Sardinie et Corsice comitique Barchinone, fuerunt pro parte aliquorum judeorum confratrum confratrie helemosine judeorum sapateriorum civitatis Cesarauguste oblata quedam capitula comodum et melioramentum dicte helemosine ut asseritur tangencia, quorum tenores sunt hii qui sequntur:

Primerament, que todo judio de la confradria que fara boda que sian tenidos los confrayres de honrrar a su boda; e qui no y yra que pague un dinero pora la dita almosna. Et si le naxere fillo que sian tenidos de yr con aquel a la circuncision; et qui no y yra que pague un dinero para la dita almosna.

Item si haura alguno de los ditos confrayres enfermo sian tenidos los adelantados qui por tiempo seran de yrlo a visitar dos dias de la sepmana, el lunes e el jueves. Et si hauran menester dineros o emprestamo sobre sospenyos quel puedan prestar entro a en quantia de cinquo solidos de los dineros de la dita almosna. Et si por aventura veran los adelantados que lo ha menester que le hayan a dar los ditos adelantados de los ditos dineros pora provision suya dos dineros por cadaun dia. Item seran tenidos todos los confrayres de yr a visitar todo sabbado al dito enfermo; et qui no y yra pague un dinero cada vegada pora la dita almosna.

Item si por ventura finara alguno de la dita confraria que sian tenidos todos los confrayres de yrle a facer honra al soterrar, et qui no y ira pague dos dineros pora la dita almosna. Item si alguno finara et sera de la dita confraria de dita almosna et lexara alguna cosa a la dita almosna sian tenidos de fazer hondra[da]ment segunt del caso sobredito. Item si por aventura el dito confrayre finara de nueyt sian tenidos los ditos confrayres de jazer en casa del muerto.

Item sian tenidos los companyeros de fazer leyr aquestos articulos dos vegadas en cadaun anyo, porque cada uno sabra que haura de fazer.

Item ninguno de la confraria que desondrara o acultara a ninguno de los confrayres que sia privado de la confraria por un mes, ultra las penas en fuero et en razon establidas. 
Item sean tenidos los ditos confrayres de seer en casa del muerto en la hora que salra desta vida. Et esto sean tenidos los ditos confrayres seguir el mas cercano parient que finara del defuncto por hueyto dias siguientes despues que sera finado a fer oracion a la sinoga, et aquel que no y yra que pague un dinero pora la dita almosna.

Qui judei predicti, oblatis dictis capitulis, nobis humiliter supplicarunt ut ipsa eis concedere ac laudare et approbare eaque observari facere de benignitate regia dignaremur. Cui supplicacioni annuentes benigne tenore presentis carte nostre perpetuo valiture per nos et nostros ex certa scientia concedimus dicte confratrie et confratribus ejusdem qui nunc sunt vel pro tempore fuerint capitula supradicta et omnia in eis contenta eaque ipsis laudamus, approbamus, ratificamus et confirmamus prout melius et plenius supra continetur. Mandantes per presentem universis et singulis judeis dicte confratrie presentibus et futuris quod dicta capitula et in eis expressata sub pena in ipsis apposita a contrafacientibus quotiens contrafactum fuerit exigenda et in dicta helemosinam convertenda ut predicitur teneant et observent et in aliquo non contraveniant.

Insuper mandamus merino Cesarauguste ceterisque officialibus nostris vel eorum locatenentibus presentibus et futuris quod concessionem nostram predictam firmam habeant et quod capitula supra inserta et omnia in eis declarata faciant per dictos judeos teneri et inviolabiliter observari, et in aliquo non contraveniant nec aliquem contravenire permittant aliqua ratione. In cuius rei testimonium presentem cartam nostram inde fieri jussimus sigillo nostro appendicio roboratam.

Datum Cesarauguste VI idus madii anno Domini MCCCXXX sexto.

G. de Villa mandato Regis facto per vicecancellarum. Signum [crucem] Petri, Dei gratia regis Aragonum etc.

Testes sunt: infans Jacobus, comes Urgelli et vicecomes Agerensis; reverendus Petrus Cesarauguste archiepiscopus; Otho de Montecatheno; Luppus de Luna; Raymundus Cornelii. Fuit clausum per Guillermum de Villa, scriptorem domini Regis.

1378, noviembre 25 (Calatayud)

El infante don Juan autoriza a la aljama de judíos de Zaragoza para que instituyan en dicha ciudad la cofradía llamada en hebreo de "Lelezmuroz».

ACA, Reg. 1684, fol. 160 v.

Documento publicado (parcialmente) por BAER: JCS, I, n. 320, que dio una signatura equivocada (Reg. 1682). 
Nos infans Johannes etc. Attendentes nobis pro parte quorundam singularium aliame judeorum civitatis Cesarauguste fuisse humiliter supplicatum, quod ipsi pro eorum comodo ac utilitate et potissime pauperum et miserabilium personarum intendunt tam de proprio elemosinas erogare, quam ab aliis gentibus pro Dei nomine bonum facere volentibus, surgendo matutinis Deum serviendo, elemosinas pauperibus et egenis pro eorum vite sustentatione necnon pro litteris adiscendis et plura alia bona faciendo, elargiri, si confratriam ordinare possent, sicuti in aliis aliamis erat fieri assuetum, ob quod supplicarunt nobis, quod sibi dictam confratriam ordinandi impartiri licenciam dignaremur [...] concedimus ac facultatem plenariam impartimur, quod confratriam rationibus predictis Dei servicium tangentibus, surgendo dictis matutinis, deinceps nuncupetur in ebrayco Lelezmuroz nominatam valeatis facere licite et impune et omnes judei que in confratria predicta esse seu intrare voluerint sint et permaneant de eadem qui inter se congregationes facere possint cum, quando et ubi eisdem videbitur faciendum et eligant personas certas que procurent et administrent omnia negocia ipsius confratrie et ducant ad lucem sive indagent omnia bona, legata et alia pia et penitencia ac utilia dicte confratrie procurent et in utilia evitent et ordinent inter illos qui in predicta confratria fuerint elemosinas et alia ad utilitatem et comodum confratrie jamdicte absque pene aliqua intrusione. Mandantes cum hac eadem gerenti vices nostris in regno Aragonum et justice regni eiusdem, baiulo generali regni eiusdem, merino Cesarauguste et aliis officialibus dicti domini Regis atque nostris ac judeis et adelantatis dicte aljame quod premissa observent et faciant observari et non contraveniant nec aliquem contravenire permittant aliqua ratione. In cuius rei testimonium presentem fieri et sigillo nostro pendenti jussimus comuniri.

Data Calataiubio... etc.

1379, noviembre 23 (Zaragoza)

Don Domingo Palomar, comisario de los judios de Zaragoza, exige a los adelantados de la cofradía [del Estudio] de dicha ciudad que en el plazo de tres dias muestren documentos que les acrediten como acreedores de la aljama de Zaragoza.

AHPZ, papeles sueltos.

Dia miercoles a XXIII dias de novienbre, plegados en las casas del honrrado don Domingo Palomar: don Juçe Almali, don Salamon Abnarrabi, Açach Almachuequi et Abraym Falleva, adelantados; don Salamon Almali, 
rabi Isçrael, don Simuel Bienviniest, don Juçe Alitienci et otros judios muytos de la dita aljama, el dito don Domingo Palomar fizo mandamiento, assi como comissario, a los sobreditos don Juçe Almali, Salamon Abnarrabi et rabi Isçrael, assi como a conffrayres de la confraria clamada [en blanco] ${ }^{357}$ que si algunas cartas tenian de la dita conffraria en que la dita aljama fues obligada en alguna cosa a la dita conffraria, que aquellas mostrasen et exhibisen luego, dentro terçero dia, por tirar todo frau que a la dita aljama se pudies fer en qualquiere manera, los conffrayres de la dita confraria en otra manera que les posava perpetuo silencio et callamiento a todos tiempos, et que ninguna cosa non pudiesen demandar los ditos conffrayres a la dita aljama del dito plazo adevant excepto una carta de deudo que se dize en que la dita aljama yes obligada a los cofrayres de la dita confraria en quantia de dos mille et çinçientos solidos jaqueses. La qual dita carta yes en tracto de conponicion et dius ciertas condiçiones si se trobara por verdat deverse pagar la dita carta o no. Et en caso do se deva pagar, que se aya a pagar en tiempo de diez annyos prorata en cada un annyo.

Testes: Sanci de Cuydaloci et Junez Trigo, judio, vezinos de la ciudat.

5

1380, febrero 6 (Zaragoza)

Cancelación de un debitorio por el que la aljama de judios de Zaragoza debía a la cofradía del Estudio de dicha aljama 2.500 sueldos jaqueses, amortizables en diez años.

AHPZ, notario Domingo Pelagut, 1380, sin foliación.

Eadem die, la dita aljama, atendient quella fues obligada en una carta ebrayca a la cofraria del Studio, ordenada en la dita aljama, en quantia de dos mille et cincientos solidos et por tacto [sic] et conponicion feyto entre los cofrayres de la dita cofraria et la dita aljama fue convenido que la dita aljama se obligas a los ditos cofrayres en tiempo de diez annyos primeros vinientes et continuo conplidos, a dar los ditos dos mille et cincientos solidos, yes a saber, dozientos et cinquanta solidos por cada uno de los ditos diez annyos, que montan la dita quantia, et que aquellos les asignassen sobre una de las rentas de la dita aljama a pagar a cierto tiempo en cada uno de los ditos diez annyos. Et la dita aljama, todos concordablement, de grado et de cierta sciencia, la dita obligacion fizieron et atorgaron; et

357 Por otros documentos (especialmente el ap. doc. 12) he podido averiguar que se trata de la cofradía del Estudio. 
prometieron conplir et servar todas et cada unas cosas et cada una dellas dius obligacion de todos sus bienes et de cada uno dellos et de la dita aljama et singulares de aquella etc.

Et luego en continent, don Juçe Almali et don Salamon Abnarrabi, regidores de la sobredita cofraria, livraron en presencia de la dita aljama la dita carta ebrayca del dito deudo de los ditos dos mille et cincientos solidos jacqueses sana, la qual dizieron que pudiese cancellar la dita aljama o otri por ella; et prometieron et se obligaron en sus nopnes proprios de haver por firme et fer ne seyer pagados a los cofrayres de la dita cofraria a todos tiempos, et de no venir ni fer venir contra las sobreditas cosas ellos ni los ditos confrayres ni alguno dellos en ningun tiempo, ni fer demanda ni question por vigor de la dita carta ebrayca a la dita aljama o singulares de aquella, dius obligacion de todos sus bienes et de cada uno dellos, mobles et sedientes, havidos et por haver en todo lugar etc. Fiat large.

Feyto up suppra.

Testes qui suppra.

El infante don Martín, a ruegos de algunos judios de Zaragoza, autoriza la institución de la cofradia de "Sombreholim», destinada al cuidado de los enfermos, en la aljama de judios de dicha ciudad.

ACA, Reg. 2089. fols. 17-17 v.

Documento encontrado por Jaume Riera.

Privilegium confratrie civitatis Cesarauguste judeorum.

Nos, infans Martinus etc. Attendientes a nos por part de algunos singulares de los judios de la aljama de la ciudat de Çaragoça fuesse humilment suplicado que a ellos, por proveyto e milloramento de los hombres pobres e miserables axi sanos como enfermos, en fazer les almoyne assi. de lur proprio como de otros que a ellos den o lexen por amor de Dios pora sostenimiento de lur vida e pora servirlos en lur enfermedat, en veylar de nueyt e de dia e darlos aquello que havran menester en la dita enfermedat, nos res menos, pora pensionar a maestro que muestre letras, a qui dell querran decullir, e muytos otros bienes fazer convernia que pudiessen ordonar confraria, segont que en otras aljamas yes costumbrada de fazer; porque supplicaron a nos que a ellos la dita confraria ordonar deviessemos licencia dar, et [sic] nos, vista la dita suplicacion e aquella recebida, que- 
rientes aquello que seria proveyto e utilidat de la dita aljama con la present carta nuestra a vos, ditos judios, empero que res de lo de iuso scripto en derrogacion de los dreytos reyales no vingua, a nuestra buena fe atorgamos e plenero poder damos a vosotros, ditos judios, que la dita confraria, por las razones sobreditas e servicio de Dios tocantes, reconoscientes e veylantes de nuyt e de dia, guardando a los miserables e enfermos, en ebrayco nombrada Sombre olim, podades fazer licitament e sines dubdo alguno. E todos los judios que en la dita confraria seredes siquiere entraran e entrar querran, sean e finquen en aquella confraria, los quales entre si aplegamiento fazer pueden por la dita razon cada e quando a ellos bien visto sera fazer, una vegada e muytas. E encara eslien personas certas que procuren e administren todos los negocios de la dita confraria. E no res menos procuren e pueden, aduguen a luz, siquiere guarden, todos [sic] bienes lexados a la dita confraria e otras cosas lexadas, convenientes e pertenicientes en proveyto e utilidat de la dita confraria. E no res menos procuren e pueden ordonar entre ellos de dar qualquiere almoynas e otras cosas que utilitat e proveyto de la confraria sobredita sea, sines pena alguna encorredera. E encara damos poder aquellos regidores o administradores qui por la dita confadria seran esleydos de costrenyer e forçar a los judios que son o seran de la dita confraria de dar e seguir aquella o aquellas cosas que por la dita confraria o las demas sera acordado o ordenado. Queremos empero e salvamos que en la dita confraria no pueden entrar ni seyer sino solament judios de la cita ciudat de Çaragoça. Mandantes, por aquesta carta nuestra, al portant vezes de governador por nos en el regno de Aragon e el justicia e baylle general del dito regno, merino de la ciudat de Çaragoça e a otros qualesquiere officiales reales e encara a los adelantados de la dita aljama, presentes e sdevenidores, que la present concession nuestra tiengan siempre e observen, segunt que otras confrarias son acostumbrados de servar en la dita ciudat, e non contravengan ni contravenir faxzan por alguna razon o manera. En testimonio de la qual cosa, mandamos la present carta seyer feyta et seyellada con nuestro seyello pendient.

Dada en Calataiud, a XXII dias de octobre en el anyo de la natividat de nuestro Senyor M CCC LXXX VII. Visa Alpi.

7

1387, noviembre 7 (Zaragoza)

El infante don Martín, atendiendo los ruegos de algunos judios de Zaragoza, les autoriza para que procedan a establecer en dicha ciudad la cofradía de "Nozé amitó", dedicada a lavar y llevar al cementerio a los judíos difuntos. 
ACA, Reg. 2089. fols. 19-19 v.

Documento encontrado por Jaume Riera.

Confratria judeorum Cesarauguste.

Nos, infans Martinus etc. Attendentes a nos, por parte de algunos singulares judios de la ciudat de Çaragoça, fuesse humilment suplicado que a ellos, por proveyto e milloramiento de los hombres pobres e miserables axi sanos como enfermos, en banyar e portarlos al cuello por enterrar quando son fenidos e passados desta present vida de almoynas, no res. menos, pora pensionar maestro que muestre letras, a qui dell querran decullir, e muytos otros bienes fazer, convernia atorgassemos que pudiessen ordonar confraria, segund que en otras aljamas yes acostumbrado de fazer; porque nos, la dita suplicacion benignament recebida, querientes aquello que sera proveyto e utilidat de la dita aljama, con la present carta nuestra a los ditos judios, empero que res de lo de suso scripto en derogación de los dreytos reales no vinga, atorgamos e pleno poder damos e atorgamos que la dita confraria, por las razones sobreditas a servicio de Dios toquantes, pueden fazer e banyar los ditos judios quando sian finados e levar en el cuello al fossar por enterrarlos, assin pobres como otros, clamado en ebrayco Noze Amita ${ }^{358}$, la qual cosa puedan fazer livramente e sines encorrimiento de pena alguna. E todos los judios qui en esta confraria entraran e entrar querran sean e finquen en la dita confraria, los quales entre si aplegamiento fazer puedan por la dita razon cada e quando a ellos bien visto sera, una vegada e muytas. $E$ encara eslian personas ciertas que procuren e administren todos los negocios de la dita confraria. E no res menos adugan a luz siquiere guarden todos [sic] bienes lexados a la dita confraria e otras cosas lexadas, convenientes e pertanascientes en proveyto e utilidat de la dita confraria. E no res menos procuren e puedan ordonar entre ellos de dar qualquiere almoynas e otras cosas que utilitat e proveyto de la confraria sobredita sea, sines pena alguna encorredora. E encara damos poder aquellos regidores e administradores qui por la dita confraria seran esleydos de constrenyer e forçar a los jodios que son o seran de la dita confraria, de dar e seguir aquella o aquellas cosas que por la dita confraria o los demas sera acordado o ordonado. Queremos empero e salvamos que en la dita confraria no puedan entrar ni seyer sino solament jodios de la dita ciudat de Çaragoça. Mandantes, por aquesta carta nostra, al portant vezes de governador por nos en el regno d'Aragon e el justicia e bayle general del dito regno, merino de la ciudat de Çaragoça e a otros qualesquiere officiales reales e encara a los adelantados de la dita aljama presentes e esdevenidores que la present concession nuestra tiengan siempre e observen, segund que otras confrarias son acostumbrades de servar en la

${ }^{358}$ La cursiva es mía. 
dita ciudat, e non contraviengan nin contravenir fagan por alguna razon o manera. En testimonio de la qual cosa, mandamos la present carta seyer fecha e con nuestro siello pendient seyallada.

Dada en Calatiu a siet dias del mes de noviembre en el anyo de la natividat de nuestro Senyor mil CCC LXXX VII. Visa Alpi.

\section{8}

1390, abril 24 (Zaragoza)

Los dirigentes de la cofradía de "Cabarim» de los judios de Zaragoza atreudan un campo situado en Corbera a Nicolás de Fuentes, alias de Breu.

AHPZ, notario Domingo Martín de Aguilón, 1390, registro, fols. 102-105 v.

Carta de atributacion de Nicholau de Fuentes alias de Breu.

Manifiesto sia a todos que nos, don Junez Trigo, cirurgico, Abraym Faleva, Salamon Avenlopiel, Avon Avenavez, jodios, adelantados de la conffraria clamada de los Caparins de la judaria de la ciudat de Çaragoça, don Salamon de la Cavalleria mayor de dias, don Juce Almali mayor de dias, don Açach Golluf mayor de dias, don Simuel Bienbinest, don Salamon Abnarabi, don Juce de Granada, rabi Salamon Jaba, rabi Jehuda Fichiel, Jehuda Avenvitas, Açach Vitales, Salamon Aborrabe, jodios confrayres de la dita conffraria de los vint deputados a regir, procurar et ministrar los bienes de la dita conffraria, de nuestras ciertas sciencias et de cada uno de nos, en el dito nombre, et certifficados plenerament de todo el dreyto de la dita conffraria en todo et por todas cosas, damos a trehudo en el sobredito nombre con comisso, loysmo et fadiga et con las condiciones dius scriptas a vos, Nicholau de Fuentes, en otra manera clamado de Breu, hun campo de la dita conffraria sitiado en Corbera, al tapiado de Badenas, termino de la dita ciudat, el qual solia tener Garcia Cosida, vezino de la dita ciudat, que affruenta con cequia mayor de Raval et con carrera publica et con el dito tapiado de Badenas, assi como las ditas afrontaciones el dito campo encierran et departen enderredor; assi aquell damos en el dito nombre a trehudo a vos, antedito Nicholau, por tiempo de cinquanta annyos primero vinientes et continuament complidos, contando de huey adelant et por precio siquiere trehudo en cada un annyo de dezehueyto solidos dineros jaqueses, buena moneda corrible en Aragon, los quales vos o los vuestros herederos o succesores, qui durant el dito tiempo de los anteditos cinquanta annyos tendran et posediran, el dito campo de suso conffrontado et designado siades tenidos dar et pagar a los adelantados de la dita confraria, qui son o por tiempo seran, por el dia [et] fiesta de Pascua Floria [sic] o hun mes 
depues, los quales compecedes a pagar a Pascua Florida primera vinient o hun mes depues et dalli adelant en cada un annyo durant el dito tiempo por el dito dia et fiesta o hun mes depues.

Et yes condicion que vos, antedito Nicholau, o los vuestros o qui quiere que durant el dito tiempo de los cinquanta annyos tendra o posedira el dito campo tengades aquell millorado et non piorado. Et otrosi yes condicion que vos, antedito Nicholau, o los vuestros, qui por tiempo seran et el dito campo tendran et posediran, dentro el dito tiempo plantedes el dito campo de suso confrontado et designado de buen bidado. Et otrosi yes condicion. que cada que el dito campo sera plantado [de] vinya que vos, sobredito Nicholau, o los vuestros, qui por tiempo seran, siades tenidos cavar et podar aquella una vegada en cada un annyo bien et suficient, por razon et en tiempo ydoneos et convinientes. Et otrosi yes condicion que vos, antedito Nicholau, o los vuestros, qui por tiempo seran et el dito campo dentro el dito tiempo tendran et posediran, como dito yes, vos paredes a decima, primicia, vinogalia et a todas et cada unas otras cargas et fazederas que daqui adelant por razon del dito campo et en aquell se havran a fazer, a las quales la dita conffraria et confrayres de aquella seriamos tenidos et obligados ante de la present atributacion excepto çut et cequia nuevas. Et otrosi yes condicion que si vos o los vuestros, o quiquiere que daqui adelant tendra o posedira el dito campo, querredes vender o por algun precio alienar o siquere el dreyto que por vigor et razon de la present tributacion havedes siquiere havredes en aquell, que la fagades a saber et la notifiquedes a los adelantados o conffrayres de la dita confaria qui por tiempo seran, diez dias ante de la vendicion o alienacion de aquell. Et si los adelantados 0 conffrayres de la dita confraria qui por tiempo seran querran en ellos retener aquell, que lo puedan fazer et la hayan la dezena part menos del precio verdadero que otri hy dara. Et si aquell la dita conffraria o adelantados de aquella retener non querran, pasados los diez dias de la fadiga lo podades vender o alienar aquell a qui querredes por aquell precio que haver ende podredes, et del precio que ende havredes, siades tenido dar et dedes a la dita conffrayria o adelantados de aquella qui por tiempo seran la dezena part del precio verdadero que otri hy dara por razon del loysmo, et este se faga tantas quantas vegadas el dito vuestro dreyto se vendra o por algun precio se alienara. Empero yes condicion que no lo podades dar, lexar, vender, enpenyar ni en alguna otra manera alienar a clerigo, cavallero, infançon ni a hombres ni fembras de orden ni de religion, ni a moro ni a jodio ni a leproso ni ad alguna otra persona, sino a personas legas, de condicion vuestra et vezinos de la dita ciudat o a fillos et herederos vuestros, ni podades en et sobre aquell instituir ni ordenar capellanya, lanpeda ni aniversario ni algunas otras cosas fazer en et por razon de aquell, por los quales el dreyto de la dita confaria et confrayres de aquella qui por tiempo seran se pudies en alguna cosa diminuir o deffraudar, ante 
aquell finque salvo a la dita conffraria et confrayres de aquella a todos tiempos sobre el dito campo et la propiedat de aquell, et las otras cosas et condiciones sobreditas [ ... ] et en el present contracto contenidas que los conffrayres o adelantados de la dita confraria qui por todo seran, como dito yes, por su propria actoridat non demandadan [sic] licencia de algun judge ecclesiatico o seglar et sines de pena et calonia alguna se puedan entrar et emperar del dito campo et de la posesion de aquell con todo el bien et milloramiento que alli feyto havredes et a do hy sera. Et vos et los vuestros siades tenidos pagar et paguedes a la dita conffraria et confrayres de aquella qui por tiempo seran todo el trehudo falido et cumplades todas las condiciones que complidas non seran etc.

Fue aquesto en la dita ciudat, a vint et quatro dias del mes de abril anno a nativitate Domini $\mathrm{M}^{2} \mathrm{CCC}^{2}$ nonagesimo, presentes tetimonios fueron a las sobreditas cosas Garcia de Biel et Açach Çamariel et Juce Alcahay, jodios habitantes en la dita ciudat.

La reina doña Violante encomienda a Hasday Crescas, "raudo sive rav" de la aljama de los judios de Zaragoza, la resolución del litigio suscitado entre las cofradias de "Cabarim" y "Bicorolim" por la posesión del treudo sobre unas casas.

ACA, Reg. 2029, fols. 168-168 v.

Yolans etc. Azday Cresques, raudo sive rau aliame judeorum civitatis Cesarauguste, gratiam suam. Exposuit nobis humiliter Jaffudanus Jaba, major dierum judeus dicte dicte [sic] civitatis, quod Jento Jaba, quondam, eius frater, attributavit quasdam domos, quas habebat in judaria civitatis predicte Azmael Avinpesat, judeo civitatis eiusdem, ad tributum sex solidorum annis singulis solvendorum cum laudimiis, faticha et comissio, quos sex solidos ipse exponens, ut heres dicti sui fratris dedit cuidam confratrie vocate de Cabarim condicione apponita, quod dicta confratria aut eius capitanei seu rectores tenerent juxta portale[m] dictarum domorum quandam tabuletam in qua scriptum esset nominem dicti Gento quondam inde nullo tempore amovendam, sicut per confratrias alias est solitum fieri pro lexis quas eis aliqui pro suis animabus faciunt seu dimittunt. Cum autem idem exponens in actu dicte donacionis dictorum sex solidorum retinuerit sibi laudimium, faticham et comissum que in ipsis domibus et tributo antea jam habebat, nuncque a paucociter tempore Çulema Avinpesat, filius dicti 
Azmael Avenpesat, non vocato ipso exponente, vendiderit dictas domos cuidam confratrie judarie jamdicte, vocate confratria de Bicurolim, et in actu dicte vendicionis confratres ipsius confratrie ammoverint tabuletam jamdictam a portali dictarum domorum. Exponens ipse, qui amotionem huiusmodi factam fuisse asserit minus debite et injuste, nobis humiliter supplicavit quod ei super hoc providere debite dignaremur. Nos, vero supplicacione huiusmodi benigne suscepta causam huiusmodi tibi ducimus harum serie comittendam. Mandantes tibi quatenus de dicta causa cognoscas et super ea vocatis et auditis partibus faciatis et decernatis, quos per jus et justiciam ac legem ebraycam fuerit faciendum procedendo super predictis breviter, summarie et de plano, maliciis et diffugiis omnibus procul pulsis. Quoniam nos, tibi super predictis omnibus et singulis et dependentibus seu emergentibus ex eisdem ac eis adherentibus seu connexis, vices nostras committimus plenarie cum presenti.

Data Cesaraguste, XXI die junii anno a nativitate Domini millesimo $\mathrm{CCC}^{\circ}$ nonagesimo primo. Dominicus Mascho.

1392, mayo 17 (Zaragoza)

Mossé Abenforna, judío de Zaragoza, ofrece garantías a Ciprés de Paternoy, a quien (junto con Facén Abullamin, Abraham Abenaçora y Jucé de Granada) acaba de vender por 1.200 sueldos jaqueses un campo de la cofradia de "Maytinal», sito en La Huerva.

AHPZ, notario Juan Blasco de Azuara, 1392, fols. 283 v.-284.

Yo, Mosse Avenforna, judio judio [sic] de la ciudat de Çaragoça, atendient que yo ensemble con Facen Agullamin, Abram Abenaçora et Juce Granada vendiemos a vos, Cipres de Paternuey, hun campo en la Guerba de los bienes de la confradria de Maytinal de la aljama de los judios de la dita ciudat por mil et cient solidos, segunt que parexe por la carta en el jueves mas cerca pasado; empero yes feyto de verdat quel dito canpo fue vendido por precio de mil et dozientos solidos, de los quales vos a mi dastes cient solidos a part, et por tal que vos non seaz engannyado en mi caso do huviesez a perder el dito campo por algun dreyto, caso [se interrumpe].

Testimonios: Gil de Blancas et Jacob Nahon, judio, habitantes en Çaragoça. 
1402, diciembre 6 (Zaragoza)

Venta de un campo sito en Miralbueno a la cofradía judía de "Cabarim" por 300 sueldos jaquesés.

AHPZ, notario Juan de Capilla, 1402, sin foliación.

De la confraria de Cabarim.

Que nos, Bernart Fores et Oria Sanchez de Palaçon, muller del, et Johan de Lacasta et Gracia Lacasta, hermanos, fillos de la sobredita Oria Sanchez et de Domingo Roldan de Lacasta, todos IIII $^{2}$ ensenble et cada uno de nos por si et por el todo vendemos et luego de present livramos a vos, los adelantados siquiere mayordopnes de la conffraria de Cabarim de la juderia de Çaragoça et a los conffrayres de la conffraria sobredita, los quales son don Benvenist de la Cavalleria, don Simuel Crexcas, don Salamon Avenlopiel et don Salamon Trigo, et a toda la confraria, a saber yes, un campo sitiado en el mont, en el termino clamado Miralbueno, del qual campo es la meytat de nos, ditos marit et muller, et la otra meytat de nos, sobreditos Johan et Gracia Lacasta, que affruenta con braçal de cabo a cabo por do se riega et con tapiado de nos, todos sobreditos, el qual es trehudero a Sant Johan del Spital, et con fosar de los moros ${ }^{359}$ et con carrera publica, por precio de trezientos solidos dineros jaqueses, los quales de vos, ditos mayordopnes et confrayres, hemos recebido por mano del dito don Simuel Crexcas ensenble con el alihara, et de aquellos bien pagados et contentos en semos etc. Et del dreyto, poder, senyorio nuestro et de los nuestros el dito campo sacamos luego de present nos en sacamos etc. Et si pleyto, question, etc. large ordine et prometemos fazer, dar actoritat en la present venda al çalmedina de la ciudat de Çaragoça en continent como en seremos requeridos.

Feyto en Çaragoça, a VI de dezienbre, anno Domini $\mathrm{M}^{\circ} \mathrm{CCCC}^{\circ}$ II.

Testes: Anthon de Albarrazin et Pascual Xemenez, de casa de Ruy Lopez Sarnes, et Abrahim Pazagon, judio corridor. Et juraron todos que non de havia feyto cession ni donacion, presentes los ditos testimonios, por la Cruz et los Evangelios.

12

1425, junio 25 (Zaragoza)

El rey Alfonso $V$ concede a la cofradía de los judios de Zaragoza llamada de

${ }^{359}$ En Zaragoza el cementerio de los mudéjares estaba próximo al de los judíos. 
la Mercé o de "Rotfecédech" licencia para que puedan recaudar en la judería fondos para su hospital.

AHPZ, papeles sueltos, 1425 .

Nos, don Alfonso, por la gracia de Dios rey de Aragon, de Sicilia, de Valencia, de Mallorques, de Cerdenya et de Corçegua, conte de Barchinona, duch de Atenes et de Neopatria et encara conte de Rossello et de Cerdanya, certificados que por socorrer a la miseria et passiones a que natura humana yes obligada et diusmessa, como son pobreza, enfermedades et otras misserias de quien el nombrar seria largo, la confraria de la aljama de los jodios de Çaragoça clamada vulgarment de la Merce et en abrayco Rotfe cedech han feyto un hospital por acoyer et recebir alli qualesquiera judios et judias assi peregrinos o strangeros como de la tierra, mendicantes, pobres et enfermos, et por conplir alli en ellos las siet obras de misericordia dandoles a comer, bever et faciendo las otras cosas a lur pobreza o enfermedat necessarias; et porque la multitud de los pobres et pelegrinos al dit hospital venientes yes tanta et las facultades de la dita confraria tan pocas que si por nos no les era misericordiossament provehido del remedio de la licencia de jus scrita no porian el dito hospital mantener ni assi pocho provedir los ditos pobres en lures necessidades, por esto, nos, querientes seer participantes en la merce, bienes et meritos que faziendo las ditas cosas se ganan, a humil suplicacion de los judios de la sobredita confraria, por tenor de la present carta nuestra a todos tiempos firme et valedera, atorgamos licencia et facultad plenera donamos a todos et qualesquiera judios de la dita confraria que, sin encorrimiento de alguna pena, toda hora et quando querran o por lo tiempo que bien visto les sera, puedan sleyr dos judios qui de quinze en quinze dias una vez vayan et puedan yr por la juderia de la dita ciudat por demandar almosnas pora sustentacion et socorrimiento de los pobres del dito hospital, et que los ditos dos hombres o judios puedan variar et mudar, cada et quando et tantas vezes quantas bien visto les sera. Mandando con esta misma carta al governador del regne d'Aragon, a los çalmedina, merino de la dita ciudat, adalantados de la dita aljama et otros qualesquiera officiales nuestros que la present nuestra licencia et concession tengan firmement et observen, et tener et observar fagan por qualesquiera officiales et subditos nuestros, sin contradiccion alguna. En testimonio de la qual cosa hemos mandado fazer la present carta nuestra con nuestro siello en pendient sellada.

Dada en Çaragoça, a vint e cinquo dias de junyo en el anyo de la natividat de nuestro senyor mil CCCC vint e [sic] cinquo, e [sic] del regne nuestro, diez. A de Funes vicecancellarius. 
Capitulaciones establecidas entre la cofradía cristiana de pellejeros y los pellejeros judios de Zaragoza.

Copia inserta en carta de traslado dada en Nápoles (Castelnovo) a 1446. III. 29 (véase ACA, Reg. 2615, fols. 81-83).

Publicada parcialmente por M. SERRANo y SANZ en Orígenes, pág. XLII.

Los capitoles infrascriptos son sehidos concordados entre los maiordomos e confrayres de la confraria de los pelliceros christianos de la ciudat de Çaragoça, de una part, e los judios pelliceros habitantes en la dicha ciudat, de la otra, los quales quieren que sian servados e tenidos e aquellos sian tenidos de tener e servar las ditas partes e cada una dellas, no obstantes qualsequiere privilegios o gracias por el senyor Rey o por la senyora Reyna, lugartinient del dicho senyor Rey, e por los jurados de la dita ciudat a los ditos mayordomos e confrayres de la dita confraria de los ditos pelliceros christianos atorgados e atorgadas:

Primerament es concordado entre las ditas partes que toda ora e quando los veyedores de la dita confraria de los peliceros christianos, qui son o por tiempo seran, querran entrar en casa o a obrador de algun judio pelicero o de otro judio habitant de la dita ciudat o en otra qualquiere cosa [sic] de aquella do algun judio forano con pelliceria possara por veyer, reconocer e visitar alguna o algunas obras e cosas de pelliceria juxta los privilegios e ordinaciones del dito officio de los pelliceros christianos, que son tenidos toda veguada clamar e haver $\mathrm{i}$ de hun vehedor judio, el qual cada un anyo los ditos peliceros judios esleiran en el tempo que los pelliceros christianos eslien los ditos sus veyedores, el qual veyedor judio haia de jurar en poder de los jurados de la dita ciudat cada un anyo, segund facen los ditos veyedores christianos, con el qual veyedor judio o, si en la dita ciudat no era, con hun otro judio pellicero qualquiere de la dita ciudat, los ditos veyedores christianos hayan a fazer la dita vesitacion siquiere reconoscimiento de obratge alguno de peliceria, segund dito es, e no sens del uno dellos.

Item es concordado entre las ditas partes que quando quiere que los ditos vehedores christianos e judio iran a veyer e reconocer ropa alguna de peliceria que sia de algun judio o judios de la dita ciudat o de fuera de la dita ciudat, que del salario o dreyto, siquiere pena o calumnia, que por causa de la dita vesitacion pertenescera a los ditos veyedores christianos, haia la terça part el dito veyedor judio.

Item es concordado entre las ditas partes que qualquiere judio del dito. 
officio de peleceria que metra o parara de nuevo tienda o obrador de peliceria en la juderia de la dita ciudat sia tenido de pagar e pague diez soldos, los quales todos integrament sian e se hayan a convertir en utilitat e proveydo del comun del ditos peliceros judios, e aquellos cullga, aplege e demande e execute e pueda executar el dito veyedor judio, e en aquesto los mayordomos christianos del dito officio, si el tal judio no querra los ditos diez soldos pagar, le den toda favor que poran, juxta su privilegio, en cobrar los ditos diez soldos.

Item es concordado entre las ditas partes que qualquiere menestral judio del dito officio que vendra a obrar a la dita ciudat, ora obre con pelicero christiano ora con pelicero judio, sia tenido pagar cinquo soldos los quales sian del comun de los ditos judios pelliceros; los quales cinquo soldos asin mismo haia de demandar e cullir el dito veyedor judio. E asi mesmo, si el tal judio no los querra pagar, que los ditos mayordomos christianos hi den toda favor que poran en cobrar aquellos.

Item es concordado entre las ditas partes que si por ventura los ditos mayordombres e veyedores e confrayres de los pelliceros christianos o alguno dellos querran o querra innovar por utilidat o necessidat del dito officio de la pelliceria o en alguna otra manera querran o querra alguna cosa de nuevo façer o alguna gracia o privilegio impetrar o haver por al dito officio, que aquesto non puedan ni pueda facer si no es con consentimento del dito veyedor judio qui la vegada sera, e encara con voluntat e consentimiento de tres otros judios del dito officio, los quales los ditos pelliceros judios esleiran desque la ora los sera notificada. E do caso que sin consentimiento e voluntat de los ditos veyedores e tres judios lo sobredito se fiziesse, que en aquell caso quieren las ditas partes que lo que asi sera feyto, quanto tocara a los ditos pelliceros judios, no valga ni tienga ni contra ellos se pueda executar; antes quieren las ditas partes que, quanto tocara a los ditos judios, agora por la ora et econtra sia por non feyto e de nenguna efficacia e valor.

Item es concordado entre las ditas partes que los veyedores christianos sian tenidos de dar al veyedor judio una clau de la puerta del corral comun de los pelliceros christianos por razon que, si por ventura alguno judio del dito officio querra obrar en el dito corral, lo pueda fazer.

Item es concordado entre las ditas partes que toda ora e quando sera trobada alguna ropa o obratge de peliceria de judio alguno, la qual no sera la que deve, que aquella se haia de jutgar por los ditos dos veyedores christianos o por el dito veyedor judio. 


\section{RESUMEN}

Mediante la utilización combinada de documentos procedentes de protocolos notariales y registros de cancillería real, y el hábil manejo de la bibliografia existente, la autora realiza un estudio sistemático y exhaustivo de las instituciones sociorreligiosas registradas en la aljama de judíos de Zaragoza en los siglos XIV-XV. En primer lugar, se estudia la sinagoga, centro de la vida pública del pueblo judío. El segundo apartado está dedicado a las cofradías y es el más extenso, pues son catorce las hermandades documentadas en la ciudad: once sociobenéficas (de asistencia al desvalido y al enfermo, de atención al estudio, de preocupación por el difunto) y tres sociolaborales (de zapateros, baldreseros y pellejeros). El trabajo se completa con la presentación y análisis de la organización hospitalaria de la aljama.

\section{SUMMARY}

The authoress, having examined the documents from notarial protocols and registers from the Royal Chancillery, besides an appropriate use of the available bibliography, makes a systematic and exhaustive study about the religious and social institutions of charitable nature which are registered in the aljama of Zaragoza during the 14th and 15th centuries. The first part of the paper is devoted to studying the most important of the Jewish institutions, the sinagogue, which was the core of Jewish community life. The second part deals with charitable institutions and it is the largest because fourteen charities recorded in that town are examined: eleven charitable organizations (devoted to helping the underprivileged, to visiting the sick, to fostering study, to performing the rites of burial) and three labour guilds (shoemakers, tawers and skinners). The paper finishes with an analysis of the community hospitals. 